\title{
LEAN STARTUP: ANÁLISE EXPLORATÓRIA SOBRE SUA UTILIZAÇÃO POR STARTUPS BRASILEIRAS
}

LEAN STARTUP: EXPLORATORY ANALYSIS ON ITS USE BY BRAZILIAN STARTUPS

\author{
Recebido em 07.02.2018 Aprovado em 11.11.2019 \\ Avaliado pelo sistema double blind review \\ DOI: https://doi.org/10.32888/cge.v7i2.12764
}

\section{Gabriel Ribeiro}

ribeirogabriel@gmail.com

MPA FGV EAESP - São Paulo/SP, Brasil

\section{Gilberto Sarfati}

gilberto.sarfati@,fgv.br

MPA/MPGC FGV EAESP - São Paulo/SP, Brasil

\section{Resumo}

Recentemente diversos empreendedores passaram a empregar uma nova abordagem na criação de empresas, denominada "Lean Startup" que, começou a ser difundida no Brasil em 2012 com o livro de Eric Ries. Com caráter exploratório, a pesquisa utiliza uma metodologia quantitativa e se vale de uma survey, respondida por 115 empreendedores, sócios de empresas de base tecnológica com até 42 meses de existência, com o objetivo de descobrir se eles conhecem a Lean Startup e o quanto suas ferramentas são adotadas. Como resultado foram encontradas sinalizações de resultados positivos obtidos pelo uso de algumas de suas ferramentas - feedback acelerado, produto mínimo viável (PMV) e métricas da contabilidade para inovação, que medem o aprendizado no lugar de lucro. Dessa forma, a pesquisa contribui com o aumento do conhecimento sobre a Lean Startup, bem como por meio da formulação de perguntas para direcionar estudo futuros.

Palavras-chave: Lean Startup, Empreendedorismo como método, Customer Development.

\begin{abstract}
Recently several entrepreneurs started to employ a new approach to business creation, called "Lean Startup", which began to be used in Brazil in 2012 with the book authored by Eric Ries. With an exploratory nature, the research uses a quantitative methodology and uses a survey, answered by 115 entrepreneurs, partners of technology-based companies with up to 42 months of existence, in order to find out if they know Lean Startup and how much the tools are adopted. Positive results were obtained by using some of its tools - accelerated feedback, minimum feasible product (PMV), and accounting for innovation metrics that measure learning rather than profit. In this way, the research contributes to increase knowledge about Lean Startup, as well as through the formulation of questions to direct future study.
\end{abstract}

Keywords: Lean Startup, Entrepreneurship as a method, Customer Development. 


\section{Introdução}

A importância do empreendedorismo para o desenvolvimento socioeconômico foi comprovada a partir da identificação de relação positiva entre a abertura de novas empresas e a geração de renda e empregos (WENNEKERS; THURIK, 1999; HALTIWANGER; JARMIN; MIRANDA, 2009; TETHER, 2000). Além disso, a criação de novos produtos e mercados quase sempre envolve o risco de perda, pois requer investimentos prévios com baixa previsibilidade dos retornos futuros (VENKATARAMAN, 1997).

Durante mais de 40 anos diversos autores buscaram formas de melhorar o processo empreendedor, mas mesmo assim a atividade continua sendo extremamente arriscada (PETTY; GRUBER, 2011). Como tentativa de aumentar a taxa de sucesso dos empreendedores, algumas práticas denominadas como "Lean Startup" ou "Startup Enxuta" têm sido adotadas por novas empresas nos últimos anos. Blank (2013) afirma que a Lean Startup reduz o risco na abertura de novos negócios, em comparação com a abordagem tradicional. Assim sendo, uma metodologia que tem potencial para aumentar a taxa de sucesso de novos empreendimentos e, por conseguinte, aumentar a quantidade de inovação produzida e o retorno dos investidores, vale ser estudada com rigor.

Ries (2012) defende que a Lean Startup pode ser aplicada tanto em novas empresas como em empresas previamente estabelecidas visando o desenvolvimento de novos produtos e serviços. Ele recomenda que hipóteses devem ser validadas com clientes reais e os esforços redirecionados de acordo com os resultados obtidos, isso tudo feito em ciclos rápidos evitando desperdícios.

A terminologia Lean Startup foi cunhada e difundida por Eric Ries com seu livro "The Lean Startup", lançado nos Estados Unidos em setembro de 2011 e no Brasil em 2012. O autor afirma que a metodologia teve origem no conceito de Customer Development (Desenvolvimento de Clientes) de Steve Blank. Entretanto, após uma análise mais profunda, percebe-se que tanto a Lean Startup, quanto o Customer Development são, na verdade, novas formas de apresentar conceitos já existentes, como a Efetuação de Sarasvathy (2001); a Cultura da Prototipagem de Schrage (2006) e o consumidor como inovador de Thomke e Von Hippel (2002), por exemplo.

Mesmo sendo um assunto constante entre empreendedores e investidores, são escassos os estudos acadêmicos que analisam a Lean Startup. Um dos poucos, é estudo alemão de Breuer (2013), que analisa aplicação das práticas dentro de grandes empresas. Entretanto, foram encontrados estudos que mapeiem o conhecimento, utilização no contexto brasileiro.

Assim, o presente estudo tem como objetivo preencher essas lacunas e, em caráter exploratório, descobrir se a metodologia Enxuta é conhecida, utilizada e se traz efeitos positivos. Dessa forma espera-se contribuir com sua difusão e aprimoramento, além de colaborar com a evolução da disciplina, sem a ambição de comprovar sua efetividade, mas caminhando nesse sentido para que estudos futuros o façam.

Diante da problemática apresentada, para atingir o objetivo mencionado, a seguinte pergunta de pesquisa é proposta: empreendedores de base tecnológica conhecem e utilizam as ferramentas da metodologia Lean Startup?

Para responder a questão o estudo é composto por um tópico de revisão teórica, em que se apresenta a evolução recente do empreendedorismo como campo de estudos até chegar à perspectiva do empreendedorismo como método. Nele também é exposta a Lean Startup e suas origens. Em seguida, discutimos a metodologia utilizada, pesquisa de caráter exploratório utilizando uma survey feita com empreendedores. A amostra é constituída por 115 sócios de empresas que estão criando um produto ou serviço inovador e têm até 42 meses de existência. Levando em conta que a técnica de seleção da amostra é não probabilística. A seguir é apresentado a análise dos dados coletados nas entrevistas. Por último, são mostradas as principais conclusões e recomendações para estudos futuros. 


\section{Referencial Teórico}

Neck e Greene (2011) afirmam que no "processo" empreendedor, está implícita a tentativa de realizar previsões enquanto o "método" não, aceitando melhor as complexidades do empreendedorismo. O presente tópico discute o assunto, dada sua relevância para distinguir o empreendedorismo como método das demais perspectivas e para contextualizar os métodos apresentados nos tópicos seguintes. Wiltbank et al. (2009) apontam duas lógicas opostas na tomada de decisão de investimento em startups: a preditiva e a de controle. Maxwell et al. (2011) utilizam a primeira ao tentar adivinhar o sucesso de startups. Estudada dentro do empreendedorismo há mais de 40 anos, de acordo com Petty e Gruber (2011), ela está construída sobre a afirmação de que, se conseguirmos prever o futuro, poderemos adotar uma posição para alcançar resultados favoráveis.

A ideia da construção de um plano de negócios possui essa lógica como pano de fundo, estando ela por trás da perspectiva processual. A premissa dessa lógica é de que se as etapas do processo empreendedor forem seguidas, as chances de sucesso aumentam. No entanto, sabe-se que empreender raramente é uma atividade linear e previsível, considerando a incerteza envolvida (VENKATARAMAN et al., 2012; SHANE, 2012).

Ao estudarem a relação entre o plano de negócios e a performance em pequenas empresas, Brinckmann, Grichnik e Kapsa (2010) defendem que a abordagem sistemática, baseada em previsões, leva a resultados superiores. Enquanto um grupo oposto de pesquisadores desafia o valor da abordagem estratégica baseada em previsões, esses propõem que se deve focar no aprendizado, na flexibilidade estratégica e no controle dos recursos, especialmente quando o grau de incerteza é alto, situação encontrada em startups.

Wiltbank et al. (2009) têm uma posição semelhante ao segundo grupo mencionado. Ambos acreditam ser melhor o uso da lógica de controle - também denominada "efetiva". Dentro desse conceito, os empreendedores procuram trabalhar com variáveis e ambientes mais controlados. Os autores afirmam que, dessa forma é possível reduzir o número de fracassos sem diminuir o número de sucessos. Os seguidores dessa lógica, não tentam fazer previsões e estabelecer objetivos, mas sim adaptar-se ao contexto que operam, transformando-o.

Ao se referir ao primeiro grupo (lógica preditiva), Blank (2013) declara que, de acordo com o conhecimento convencional, a primeira coisa que um fundador deve fazer é um plano de negócios um documento estático que descreve o tamanho da oportunidade, o problema a ser resolvido e a solução que o novo empreendimento vai desenvolver. Normalmente, trata-se de uma pesquisa em dados secundários, feita em isolamento, antes que o empreendedor comece a desenvolver o produto e inclui uma projeção de fluxo de caixa de cinco anos. Essa abordagem parte da premissa de que é possível prever a maioria das incertezas de um negócio.

Após obter os recursos, o empreendedor começa o desenvolvimento da solução, da mesma maneira isolada em que foi feito o plano de negócios e falando pouco ou nada com clientes. Somente após tudo pronto, quando a força de vendas vai tentar efetivamente vender, é que se coleta feedback dos clientes. Nesse momento, o empreendedor pode descobrir que os clientes não valorizam a maioria dos atributos de seu produto (BLANK; DORF, 2012).

Brinckmann, Grichnik e Kapsa (2010) relatam que existe um debate no campo do empreendedorismo sobre o valor do plano de negócios. Entretanto, são escassas as evidências empíricas que possam fundamentar os argumentos de qualquer escola de pensamento.

Gruber (2007) testou, em uma amostra de 100 startups alemãs que foram apoiadas por VCs, a hipótese de que planos de negócios possuem impacto positivo no resultado das empresas. A análise corroborou a hipótese, mesmo em ambientes mais dinâmicos, onde seu uso é mais questionado. Porém, o autor sugere que, para esse tipo de ambiente, deve ser utilizado um entendimento mais adaptativo (abordagem de "toolkit" semelhante aos métodos de Venkataraman et al., 2012), ou seja, focar em algumas atividades selecionadas e acelerar as atividades de planejamento.

Gruber (2007) destaca em seu estudo que o valor obtido por meio do planejamento varia de acordo com o ambiente em que a empresa é fundada, o tipo de atividades desenvolvidas no planejamento e 
o esforço dedicado às atividades específicas. A análise do autor indica que em ambientes muito dinâmicos, empreendedores obtém mais valor quando seu foco está em coleta de informações, decisões de marketing-mix e planejamento do relacionamento com os clientes. Em ambientes menos dinâmicos, empreendedores que passam mais tempo planejando obtém resultados superiores.

Após anos trabalhando como empreendedor, investidor e pesquisador de empreendedorismo, Blank (2013) afirmou que raramente um plano de negócios sobrevive ao primeiro contato com os clientes. Em uma análise superficial, poderíamos entender que Gruber (2007) defende uma posição contrária. Entretanto, para Blank (2013) e Ries (2012), a definição de plano de negócios é de um esforço muito grande feito isoladamente (sem contato com clientes). Por outro lado, Gruber (2007) defende a ideia de que startups devem dar foco para algumas partes específicas do planejamento e realizá-lo com rapidez. Em sua opinião, o intervalo de tempo entre o planejamento e o feedback é muito mais curto e mais transparente do que em empresas estabelecidas, semelhante ao conceito de "ciclos curtos" da Startup Enxuta de Ries (2012).

Outro estudo utiliza uma terminologia diferente, mas chega a conclusões semelhantes às de Blank (2013) e Ries (2012): trata-se de uma meta análise de 46 estudos passados (11.046 organizações) feita por Brinckmann, Grichnik e Kapsa (2010) sobre a efetividade do plano de negócios. Os autores concluíram que tal ferramenta aumenta o desempenho de empresas novas e de empresas estabelecidas. Contudo, diferentes fatores moderam a força do relacionamento. Em uma amostra de pequenas empresas, planos de negócios tiveram relacionamento mais forte com a performance nas empresas já estabelecidas. Sendo assim, os autores constataram que fatores contingenciais - como incerteza, limitação nas informações históricas e inexistência de estrutura para planejamento dos negócios e procedimentos - podem limitar o retorno do plano de negócios. Baseados nessas descobertas, os autores sugerem a abordagem concomitante e dinâmica de planejamento, aprendizado e execução.

Blank (2007) e Ries (2012) afirmam que o conceito de "Customer Development" foi de onde originouse a Lean Startup. Embora essa afirmação possa ser questionada, conforme os próximos tópicos do presente estudo, antes de detalhar a Lean, é importante entender o Customer Development ou Desenvolvimento de Clientes. Metodologia essa, que começou a ser desenhada de forma empírica, quando Blank (2007) trabalhou como consultor para duas empresas de Venture Capital (VC) e, ao mesmo tempo, atuou como membro do conselho de duas startups. O autor já tinha participado da fundação de diversas empresas; entretanto, ele afirma que, nessa situação, deixou de estar envolvido pessoalmente e se tornou um observador sem a paixão de um fundador. Dessa forma, começou a notar alguns padrões e isso o fez pensar se esse conhecimento não poderia ser estruturado e replicado. A conclusão a que Blank (2007) chegou foi que as startups que sobrevivem não seguem o modelo tradicional de lançamento centrado no produto - elas acabam "inventando" por tentativa e erro, demitindo e contratando, um processo paralelo ao desenvolvimento de produto. Trata-se de um processo de aprendizado e descoberta do cliente - denominando Desenvolvimento de Clientes, paralelo ao Product Development.

Para o autor, a metodologia serve para responder alguns problemas comuns no lançamento de novos produtos: onde está nosso mercado? Quem são nossos consumidores? Como montamos o time certo? Como escalamos as vendas?

Blank (2007) entende que a maioria das empresas atuais, para introduzir novos produtos, utiliza metodologias com foco nos processos internos da empresa, enquanto o input dos clientes é visto como um checkpoint, e não um direcionador. Para o autor, as metodologias atuais não oferecem previsão e orientação sobre o comportamento do consumidor, por isso precisamos construir um novo processo. Ainda na visão de Blank (2007), a saída está em ouvir mais os potenciais clientes, indo a campo e investigando suas necessidades e as características dos mercados antes de se comprometer com um caminho e especificações detalhadas do produto, dai seu lema "Get Out of the Building!" (BLANK; DORF, 2012).

Blank (2007) destaca também que o desenvolvimento de clientes tem uma limitação importante: não é aplicável a mercados nos quais os clientes são garantidos como, por exemplo, em biotecnologia, saúde e energia. Ele é importante para ajudar a entender os comportamentos relacionados à adoção 
do produto e, caso essas questões não sejam consideradas críticas para um lançamento, a aplicação da metodologia é considerada uma perda de tempo. Após uma visão geral do Desenvolvimento de Clientes, é possível um aprofundamento nos conceitos da Lean Startup.

Blank (2013) relata que, por volta de 2003, começou a divulgar o conceito de desenvolvimento de clientes e, em 2004, ao investir em uma empresa fundada por Eric Ries e Will Harvey, impôs a condição de que eles participassem de uma turma de seu curso. $\mathrm{O}$ autor afirma que, rapidamente, Ries percebeu que o modelo de desenvolvimento waterfall deveria ser substituído - ele enxergou similaridades nas disciplinas que estavam surgindo no empreendedorismo, principalmente no desenvolvimento ágil e no desenvolvimento de clientes com o modelo Toyota de Produção, o Lean Manufacturing. Diante desse contexto Ries publicou, em 2011, o "The Lean Startup" e, em 2012, Bob Dorf e Blank publicaram o The Startup Owner's Manual, reforçando a metodologia da Lean Startup.

Blank e Dorf (2012), Blank (2013), Ries (2012) e Breuer (2013) argumentam que empresas estabelecidas executam um modelo de negócios, enquanto startups procuram por um. Essa definição está no cerne da abordagem Enxuta e a partir dela surge a definição de Lean Startup: uma organização temporária projetada para procurar um modelo de negócios repetível e escalável. Blank (2013) concorda com Shane e Venkataraman (2000) e Venkataraman et al. (2012) ao afirmar que as escolas de negócios, ao perceberem a diferença mencionada acima, passaram a entender que novos negócios precisam de suas próprias ferramentas.

Uma vez que a Lean Startup é uma metodologia baseada na ideia de que se deve falhar rápido e valorizar o aprendizado (validado) contínuo, ela favorece a experimentação em detrimento ao planejamento elaborado, feedback do cliente em relação à intuição e design interativo sobre design tradicional feito totalmente antes do contato com clientes (RIES, 2012; BREUER, 2013).

Blank (2013) defende que a metodologia da Lean Startup transforma o processo de abertura de um novo negócio em uma atividade menos arriscada. Após observar centenas de empreendimentos, o autor constatou que a utilização da metodologia por si só não garante o sucesso de uma empresa individual, mas, aplicá-la em um portfólio de empresas, resultará em menos falhas do que o método tradicional.

Blank (2013) entende que o método enxuto tem três princípios fundamentais: o primeiro é que, no lugar de meses de planejamento e pesquisa, os empreendedores devem aceitar que no início só possuem uma série de hipóteses não testadas. O segundo, já mencionado, é que as startups enxutas devem utilizar a abordagem de "sair do prédio", também denominada "desenvolvimento de clientes" para testar as hipóteses, em que se deve procurar possíveis usuários, compradores e parceiros para obter feedback sobre todos os elementos do modelo de negócios, funcionalidades do produto, precificação, canais de distribuição e estratégias para aquisição de clientes. O terceiro é que novos empreendimentos devem construir rapidamente um produto mínimo viável, buscar feedback dos clientes e fazer o desenvolvimento de forma incremental. Utilizando os feedbacks, as hipóteses devem ser alteradas, pequenas mudanças são denominadas "iterações", enquanto as grandes, que mudam radicalmente a direção, são chamadas de "pivotagens". O autor reconhece que uma startup provavelmente vai falhar diversas vezes antes de acertar. Baker e Nelson (2005) afirmam que o dinamismo e a incerteza do contexto, requer que o empreendedor continuamente repense a estratégia adotada e a estrutura da organização.

Embora Blank (2013) não mencione, certamente o Desenvolvimento de Clientes e a Lean Startup tiveram influência de outros autores. Ries (2012) e Blank (2007) não inventaram uma metodologia nova e revolucionária, o mérito deles está em ter agrupado uma série de ferramentas existentes, utilizando uma linguagem simples e acessível para os empreendedores.

A teoria que aparentemente mais inspirou Ries (2012) e Blank (2007) é denominada "Effectuation" ou Efetuação, segundo a qual os empreendedores devem utilizar o modelo de decisão da Efetuação no lugar da Causalidade (ou Causation). Considerada uma das técnicas da perspectiva teórica do empreendedorismo como método por Venkataraman et al. (2012) e Salusse (2014), foi desenvolvida inicialmente por Sarasvathy (2001). Para a autora, Causation é uma lógica que está relacionada à previsão e Effectuation ao controle.

Shane e Venkataraman (2000) e Sarasvathy (2001) afirmam que as decisões em economia e negócios 
abordam, em diversos níveis, indivíduos, empresas e indústrias. Mas, o problema, é que muitas vezes se assume a existência prévia de tais elementos, sem abranger o processo de criação. Sarasvathy (2001) nos dá alguns exemplos de questões raramente exploradas: a) como tomar decisões de precificação se a empresa não existe (não há dados sobre receitas e custos)? b) como contratar alguém se a empresa não existe? c) como fazer valuation de empresas em indústrias que não existiam alguns anos atrás e ainda estão se formando?

Essas questões envolvem o problema de escolher efeitos particulares que talvez não cheguem a objetivos determinados. Por exemplo: quando se sabe exatamente que tipo de empresa se deseja construir, é possível utilizar dados existentes. O problema é que normalmente os empreendedores, quando começam um negócio, possuem uma ideia demasiadamente ampla (SARASVATHY, 2001).

Quando o empreendedor sabe claramente qual mercado irá capturar, pode utilizar técnicas de pesquisa de opinião e formular estratégia para penetrá-lo, afirma Sarasvathy (2001). Blank (2007) e Ries (2012) corroboram a posição de Sarasvathy (2001) de que tais práticas fazem sentido para empresas estabelecidas, mas não funcionam bem para startups ou lançamento de produtos para novos mercados em empresas já estabelecidas.

Sarasvathy (2001) esclarece que o processo de Causation toma um efeito em particular como dado e foca nos meios para criá-lo. O processo de Effectuation assume uma série de meios como definidos e concentra-se na seleção entre possíveis efeitos que podem ser criados com esse conjunto de meios. Ambos fazem parte do raciocínio humano e podem ocorrer simultaneamente, sendo que o autor os coloca em justaposição para facilitar o entendimento.

Segundo Chandler et al. (2011), um tomador de decisão que utiliza a lógica de Causation enxerga a incerteza como algo negativo, enquanto a experimentação - uma sub-dimensão da Efetuação - está positivamente correlacionada com as incertezas.

A possibilidade de chegar a lugares, a princípio, desconhecidos é semelhante à ideia de "pivô" de Ries (2012) e à própria definição de Blank (2007) de startup como organização que tem como objetivo aprender. Sarasvathy (2001) assegura que, mesmo que a ideia inicial não tenha sucesso, escutando continuamente os clientes e construindo uma crescente rede de consumidores e parceiros estratégicos, o empreendedor pode identificar oportunidades interessantes para trabalhar. Ele afirma que o decisor pode mudar seus objetivos no meio do caminho, podendo até construí-lo ao longo do tempo, fazendo o uso de contingências à medida que elas surjam.

Sarasvathy (2001) defende que existem quatro princípios que definem a lógica da efetuação: a) Perda aceitável - em vez de estabelecer retornos esperados utilizando a lógica da Causalidade, o empreendedor deve avaliar o quanto ele aceita perder. b) Alianças estratégicas - mais importante do que fazer análise competitiva é identificar e estabelecer alianças estratégicas. Esse princípio enfatiza o valor do estabelecimento de compromissos prévios como forma de eliminar a incerteza. Blank (2007) e Ries (2012) concordam com sua importância. c) Explorar contingências - segundo esse princípio, deve-se explorar contingências no lugar de conhecimento preexistente. Quando um conhecimento já existente for considerado uma fonte de vantagem competitiva, ele deve ser utilizado; se não for esse o caso, o autor recomenda que as contingências que surgem inesperadamente é que devem ser exploradas. d) Controlar o futuro imprevisível - o autor defende que isso é melhor do que tentar prever um futuro incerto. O lema é "na medida em que posso influenciar o futuro, não preciso prevêlo". Com a utilização de compromissos prévios, por exemplo, torna-se desnecessário tentar prever o futuro em alguns casos.

A prototipagem não é um conceito novo. Schrage (1993) já falava sobre sua importância para melhorar o desenvolvimento de produtos. Todavia, a ferramenta ganhou popularidade nos últimos anos, à medida que os softwares evoluíram, pois, essa indústria os utiliza amplamente (RIES, 2012).

Schrage (1993) conta que praticamente todos os projetos inovadores surgem da interação de duas formas de representação, uma lista de desejos e um protótipo. O autor defende que as empresas devem implementar uma "cultura de prototipagem", através de uma mistura de processos formais e informais. O autor argumenta, ainda, que empresas nascentes tendem a ser mais orientadas por tal ferramenta, dado o custo muito inferior do que o desenvolvimento completo de um produto. 
Dey, Abowd e Salber (2001) afirmam que protótipos colocam o produto em um contexto, ou seja, em uma situação relacionada à interação entre humanos, aplicações e o ambiente, daí sua importância. Os autores complementam que muitas vezes a prototipagem serve para revelar que os consumidores valorizam características diferentes das esperadas inicialmente.

Schrage (1993) ressalta a importância de ciclos rápidos de prototipagem, pois como o tempo para lançamento de produtos é fonte de vantagem competitiva, a velocidade contribui nesse sentido. Além disso, para o autor, quanto mais ciclos forem feitos, mais adequados às necessidades dos clientes serão os produtos. Blank e Dorf (2012) e Ries (2012) concordam com a importância de acelerar tal atividade para obtenção de feedback. Seu conceito de produto mínimo viável é uma espécie de protótipo oferecido aos clientes para a obtenção de feedbacks utilizando o mínimo possível de recursos. Schrage (1993) diz a mesma coisa, mas sem utilizar a terminologia de "produto mínimo viável".

\section{Procedimentos metodológicos}

O intuito do presente estudo é entender de forma exploratória se a metodologia da Lean Startup está sendo utilizada por empreendedores brasileiros e se está trazendo efeitos positivos. De forma alguma pretende-se afirmar que as evidências encontradas são válidas para todos os empreendedores brasileiros. Objetiva-se aumentar a compreensão sobre um fato particular esperando abrir caminho para estudos futuros.

Quanto à abordagem metodológica geral, com o objetivo de responder às questões de pesquisa, o estudo foi desenvolvido com o método quantitativo de caráter exploratório. A coleta de dados foi conduzida através de um estudo tipo survey, utilizando um questionário estruturado, que foi enviado por e-mail para 510 empreendedores. Das 137 respostas obtidas, 115 foram consideradas válidas.

O presente estudo faz uso da teoria como uma lente ou perspectiva teórica, apontada como uma das formas de utilizar-se a teoria em pesquisas qualitativas por Creswell (2010). O autor observa que essas lentes guiam os pesquisadores com relação às questões importantes para serem examinadas.

No presente estudo foi utilizada uma amostra não probabilística. Alreck e Settle (1995) destacam que na amostra aleatória os indivíduos da população não possuem a mesma chance de serem escolhidos. Saunders, Lewis e Thornhill (2009) explicam que, embora não seja a melhor alternativa, ela pode ser utilizada em pesquisas exploratórias, desde que não sejam feitas generalizações das conclusões obtidas, como se fossem válidas para toda a população. A amostra não probabilística foi escolhida considerando-se a dificuldade em selecionar empreendedores de forma aleatória, principalmente por não existir uma listagem de todos os empreendedores para que possa ser feito um sorteio.

Saunders, Lewis e Thornhill (2009) destacam que, para amostras não probabilísticas, não existe uma regra para determinar o tamanho da amostra. Sendo assim, foram convidados para responder a pesquisa 510 sócios de startups de base tecnológica, com até 42 meses do início do projeto. Obtevese uma taxa de resposta de 27\% (137 pessoas), sendo que, dessas, 115 foram consideradas válidas.

Dentre as 510 empresas, 76 foram vencedoras de uma das 3 edições do concurso Startup Brasil, uma iniciativa do Governo Federal, criado pelo Ministério da Ciência, Tecnologia e Inovação para apoiar startups de base tecnológica; 33 foram finalistas do concurso DEMO Brasil 2014 - concurso que há 24 anos impulsiona importantes empresas nos Estados Unidos, tais como Waze, Salesforce.com, Picasa, Skype, Webex e Tivo, de acordo com o site do evento (DEMO BRASIL, 2014).

As demais foram contatos do pesquisador e indicações de pessoas próximas ao pesquisador ou obtidas através do método snowball, pois uma das questões solicitava que os empreendedores indicassem outros sócios de startups para que também respondessem ao questionário. Saunders, Lewis e Thornhill (2009) afirmam que a técnica de amostragem snowball é comumente utilizada quando é difícil de encontrar membros da população desejada, como é o caso da presente pesquisa.

Considerando a dificuldade em encontrar os indivíduos, o pesquisador postou questionário em grupos de startups de redes sociais, mas, devido à baixa adesão e à falta de controle da amostra e de quem realmente respondeu, os cinco questionários obtidos através desse meio foram desconsiderados. Foram desconsiderados também 12 questionários incompletos e cinco questionários de 
empreendedores que abriram seus negócios há mais de 42 meses, uma vez que suas empresas já não são consideradas startups, de acordo com o critério da OECD (AHMAD; SEYMOUR, 2008), restando assim 115 respostas válidas.

Para responder as perguntas da pesquisa, sob a luz da teoria, foram identificadas variáveis independentes, dependentes e demográficas. Segundo Alreck e Settle (1995), quando analisamos pares de variáveis, são possíveis dois resultados: elas podem mover-se juntamente, indicando que estão relacionadas, ou podem mover-se de maneira completamente aleatória, indicando que não existe relacionamento entre as duas.

Alreck e Settle (1995) afirmam que surveys podem servir para capturar informações sobre diversos tópicos divididos em oito categorias: atitudes, imagens, decisões, necessidades, comportamento, estilo de vida, afiliação e dados demográficos. As variáveis independentes nesse estudo buscam predominantemente avaliar comportamento, pois perguntamos como o empreendedor age. Alreck e Settle (1995) entendem que, para mensurar esse tipo de informação, são feitas questões sobre o que os respondentes fizeram ou não, onde tomaram as ações, quando e com qual frequência. Já as variáveis dependentes servem para capturar a imagem verbal dos respondentes sobre algum tópico (ALRECK e SETTLE, 1995).

Como variáveis independentes, foram utilizadas as práticas que Ries (2012) utiliza para descrever a Lean Startup, já descritas na revisão teórica: métricas da contabilidade para inovação; validação de hipóteses a partir das métricas; produto mínimo viável; pivô no modelo de negócios; ciclo de feedback acelerado e aprendizado como objetivo da Startup

De forma semelhante às variáveis independentes, foi construído um índice atribuindo uma pontuação para cada resposta. Os pontos foram somados para cada empresa e, quanto mais alto o resultado, mais maduro é considerado o modelo de negócios.

Com o objetivo de descrever a amostra, foram coletadas variáveis demográficas. O questionário pela internet foi escolhido como ferramenta de pesquisa comparando as características dessa ferramenta listadas por Saunders, Lewis e Thornhill (2009) com as características dos indíviduos da amostra, das informações necessárias para responder as questões de pesquisa e das características dos recursos disponíveis pelo pesquisador:

Para aumentar a validade do questionário, Saunders, Lewis e Thornhill (2009) determinam que as questões devem ser claras e os leitores devem estar familiarizados com as palavras utilizadas. Considerando essa recomendação, o presente estudo avalia a adoção de práticas da Lean Startup sem mencionar diretamente os nomes das ferramentas, dessa forma, mesmo quem nunca ouviu falar das práticas consegue responder. Essa abordagem também ajuda a diminuir outra fonte de viés que é o desejo de aceitação social mencionado por Alreck e Settle (1995), pois fica mais difícil identificar o que seria "a resposta correta".

O presente estudo faz uso somente de questões fechadas. Saunders, Lewis e Thornhill (2009) reconhecem que esse tipo de questão é mais fácil e rápido de ser respondido, além de permitir mais facilmente a comparação entre os respondentes.

Para dar a impressão de redução do tamanho do questionário Saunders, Lewis e Thornhill (2009) falam que pode ser usada uma matriz, com esse objetivo as variáveis dependentes foram mapeadas com apenas a questão número 12, feita nesse formato e com as respostas em escala Likert de 5 pontos. Uma limitação do instrumento de coleta de dados utilizado no presente estudo é que, quando uma questão não é bem compreendida, o autor não tem a chance de acompanhar e intervir. Além disso, em questionários online só existe uma chance de a informação ser obtida, pois é difícil entrar em contato com os respondentes para questões adicionais. Logo, deve ser feito um planejamento da informação que serão coletadas e como serão analisadas, para garantir que as questões de pesquisa sejam respondidas (SAUNDERS, LEWIS E THORNHILL; 2009). Para minimizar o risco desse tipo de evento foi feito um pré-teste com 5 empreendedores.

O objetivo do pré-teste foi refinar o questionário para evitar que os respondentes tenham problemas ao responder. Além disso, ele permite uma avaliação da validade das questões e da confiabilidade da informação coletada (SAUNDERS, LEWIS e THORNHILL, 2009). Como parte do pré-teste, foi 
feita a análise preliminar dos dados para garantir que as informações coletadas poderiam ser analisadas e que iriam responder as questões de pesquisa conforme recomendação de Saunders, Lewis e Thornhill (2009).

O pré-teste trouxe algumas conclusões importantes, inicialmente o pesquisador pretendia aplicar duas questões sobre cada variável da Lean Startup, mas depois percebeu que isso iria deixar o questionário longo, confuso e ainda iria gerar irritação por parte dos respondentes, diminuindo a taxa de resposta. Sendo assim as questões de validação foram eliminadas. Outra mudança feita a partir do pré-teste foi a separação em blocos e adaptação do questionário para uma sequência que fazia mais sentido para os respondentes. Inicialmente as questões estavam ordenadas em blocos de variáveis dependentes, independentes e demográficas, isso confundiu os entrevistados.

A coleta de dados foi feita em setembro e início de outubro de 2016. Primeiramente foi enviado um convite enviado via e-mail, apresentando o pesquisador, objetivo do estudo e um link para a página web do site especializado em surveys (Survey Monkey).

Após dois dias, foi enviado um segundo e-mail com um lembrete para as pessoas que não haviam respondido. Dois dias após o lembrete, foi enviado um terceiro e-mail para aqueles que ainda não haviam respondido, passando senso de urgência e informando que se tratava do último dia para responder a pesquisa.

No presente estudo a análise foi realizada individualmente para cada um dos três tipos de variáveis e depois foi feita uma análise exploratória acerca da relação entre as variáveis dependentes (índice que mede a maturidade do modelo de negócios) e as variáveis independentes (utilização das técnicas da Lean Startup). Considerando que a obtenção de recursos de terceiros também demonstra uma maior maturidade da empresa (não significa que quem não recebeu recurso tem uma menor maturidade), o relacionamento dessa variável com a adoção das práticas Lean também foi analisado. Com relação às variáveis demográficas, para caracterizar o perfil dos respondentes foram utilizadas algumas estatísticas descritivas: média, moda, desvio padrão e frequência. Para demostrar de forma gráfica foram utilizados diagramas de dotplot, boxplot, histograma e tabela de frequência.

As questões que investigam as variáveis independentes já respondem por si só as questões de pesquisa: a) O quanto suas ferramentas são adotadas? b) Os empreendedores conhecem a metodologia da Lean Startup? Para analisar de forma exploratória a relação de dependência entre as variáveis e responder a questão “c) O uso de práticas da Lean Startup levam a modelos de negócios mais maduros?”, foram utilizadas as seguintes técnicas: análise de tabulação cruzada, coeficiente de correlação, regressão linear múltipla e regressão logística binária (probit). Para complementar a análise foram utilizadas algumas ferramentas gráficas como boxplot e gráfico de intervalo.

Alreck e Settle (1995) explicam que a análise de tabulação cruzada é o cruzamento de duas variáveis em uma tabela, com o objetivo de ver se a distribuição de uma variável difere significativamente para cada valor ou nível da outra variável. Os autores afirmam que essa técnica é popular, pois ela é fácil de ser feita e de ser interpretada.

Para avaliar a força da relação entre as variáveis foi utilizado o coeficiente de correlação (r). Saunders, Lewis e Thornhill (2009) afirmam que ele pode assumir valores entre -1 e +1 , sendo que +1 representa uma correlação perfeitamente positiva, ou seja, quando o valor de uma variável sobre o valor da outra também sobe, ou -1, que representa uma correlação perfeitamente negativa. Valores próximos a zero significam que as variáveis são independentes. Os autores recomendam que seja verificado se os resultados obtidos não foram por acaso, isso é feito observando-se o p-valor, que deve ser inferior a 0,10 .

Foi feita também uma regressão logística binária (probit), utilizando como variável dependente a "captação de recursos de terceiros", como respostas possíveis são "sim ou "não" (categóricas) foi utilizada esse tipo de regressão no lugar da linear múltipla que é recomendada quando a variável de resposta é numérica continua.

Nas duas regressões os principais elementos observados foram os p-valores, que quando menores do que 0,10 significam que o relacionamento não é ao acaso (rejeita a hipótese nula), e os coeficientes, não o tamanho dos coeficientes, mas sim seus sinais - que indicam relacionamento positivo ou negativo. Para gerar os modelos foi utilizado o software Minitab 17. 


\section{Apresentação e análise dos resultados}

Antes de analisarmos os resultados sobre a utilização das práticas Lean, são apresentadas as variáveis demográficas. Uma variável importante para entendermos o perfil da amostra é a idade das empresas, por isso foi perguntado o tempo que havia se passado desde o início do planejamento até a data atual. Em média as empresas começaram o planejamento há 22 meses, com um desvio padrão de 10 meses. Quanto ao tipo de produto o serviço oferecido, $82 \%$ dos empreendedores afirmaram que seu produto/serviço é totalmente virtual e $18 \%$ é misto, com entrega física mas grande importância da experiência virtual. Seis empreendedores responderam que seu produto era somente físico, entretanto ao visitar o website das empresas o pesquisador verificou que quatro deles na verdade eram mistos, sendo assim foram reclassificados. Dois deles realmente eram físicos e, portanto, foram excluídos da amostra, considerando que o presente estudo tem como público alvo startups de base tecnológica.

Os empreendedores foram questionados também sobre os investimentos feitos na startup, do total, $52 \%$ não captaram recursos de investidores e empréstimos, investindo somente recursos próprios. Desses, $41 \%$ informaram o montante dos investimentos próprios, que é em média $\mathrm{R} \$ 41$ mil (desconsiderando os outliers), com um desvio padrão de $\mathrm{R} \$ 30$ mil.

Do total de empreendedores, $48 \%$ captaram recursos de terceiros, desses, $51 \%$ informaram o valor captado, sendo em média $\mathrm{R} \$ 253$ mil (desconsiderando os outliers), com desvio padrão de $\mathrm{R} \$ 186$ mil. A média do total de investimentos (investimentos próprios somados aos investimentos de terceiros) é de $\mathrm{R} \$ 179$ mil, com desvio padrão de $\mathrm{R} \$ 189$ mil e mediana em $\mathrm{R} \$ 83$ mil.

Ao analisarmos o total de investimentos nas empresas da amostra, vemos que existem 4 outliers, são empresas que tiveram investimentos de 1 milhão, 3 milhões, 3,8 milhões e 4,4 milhões. Sendo assim, elas foram desconsideradas para o cálculo das estatísticas descritivas.

Os empreendedores foram questionados também quanto ao atual estágio de desenvolvimento do principal produto ou serviço oferecido, podemos observar na tabela abaixo que $84 \%$ possuem seu produto finalizado.

Cerca de 68\% dos respondentes afirmam que já participaram da abertura de outras empresas anteriormente. Quanto a experiência como empreendedor, a média foi de 6,8 anos com um desvio padrão de 6,9 anos, mediana em 4 anos e moda em 2 anos (19 indivíduos). A grande maioria (82\%) dos empreendedores possui até 10 anos de experiência. Como penúltima questão, foi perguntado se os respondentes conheciam os conceitos da "Lean Startup" do Eric Ries e apenas 8 pessoas (7\%) afirmaram que não conheciam. Essa questão foi feita no final para não influenciar nas outras respostas. Para os empreendedores que falaram que conheciam a metodologia, foi perguntado através de quais meios elas aprenderam. Como os entrevistados podem ter utilizado mais de um meio para o aprendizado, foi permitida a seleção de múltiplas respostas. Podemos observar na tabela abaixo que as quatro principais formas de aprendizado sobre a Lean Startup são: livro, matéria na internet, vídeos na internet e palestras.

Além desses, alguns respondentes falaram que aprenderam com outras pessoas, na prática ou por terem participado de algum processo de aceleração.

Foram feitas 6 questões para mapear a adoção da abordagem da Lean Startup pelos empreendedores respondentes. A primeira delas foi a questão sobre o tempo que levou do início do planejamento até o primeiro teste com cliente. Para Ries (2012), os empreendedores devem eliminar o desperdício de tempo e recursos no processo de validação do aprendizado, sendo assim, quando mais cedo os testes com clientes, mais aderente ao Lean é a empresa. A média de tempo até o primeiro teste foi de 6,6 meses, mediana de 5 meses e primeiro quartil em 3 meses. A segunda questão sobre o uso de práticas consideradas Lean sobre a principal métrica utilizada para avaliar o desempenho do negócio. Considerando que o principal objetivo das startups é o aprendizado, não faz sentido medir a empresa pelo seu lucro, os autores falam que devem ser utilizadas medidas do aprendizado e menciona algumas 
delas: taxa de conversão, valor do cliente, custo de aquisição de um cliente, coeficiente viral e retenção. Cerca de $65 \%$ dos respondentes utilizam as métricas recomendadas pelo autor.

Na visão de Ries (2012) e Blank e Dorf (2012) as métricas devem ser utilizadas para gerar aprendizado validado. Hipóteses devem ser estabelecidas e as métricas validam tais hipóteses. Como forma de mapear essa abordagem na amostra, foi perguntado aos empreendedores se a principal métrica guiou alguma mudança no modelo de negócio, produto ou serviço nos últimos meses e $79 \%$ do total de empreendedores responderam que sim.

A quarta questão sobre as práticas da Lean Startup teve como objetivo mensurar a utilização do "produto mínimo viável" que na visão de Ries (2012), serve para eliminação de desperdícios na obtenção de feedback dos clientes sobre o produto ou serviço. Questionamos qual estágio de maturidade estava o produto/serviço nos primeiros testes com clientes. Quanto mais inicial o estágio de desenvolvimento para conseguir o feedback, mais próxima da Lean Startup foi considerada a prática. Cerca de $45 \%$ dos empreendedores utilizaram em seus primeiros testes um protótipo ou simulação da experiência.

A quinta questão teve como finalidade identificar se o modelo de negócios já passou por muitas iterações e pivotagens. Ries (2012) e Blank e Dorf (2012) enxergam de maneira positiva a empresa passar pelos pivôs e iterações, pois entende que o modelo de negócios vai aperfeiçoando-se. Pudemos observar que $46 \%$ dos empreendedores reconhecem ter mudado muito seus modelos de negócios.

A última questão foi sobre a percepção quanto a concordância com um dos conceitos base da Lean Startup, a afirmação de que o principal objetivo de uma startup é o aprendizado (BREUER, 2013; BLANK; DORF, 2012; RIES 2012). Foi observado que 71\% dos respondentes concordam que o principal objetivo de suas empresas é o aprendizado.

Com o objetivo de responder a questão "c) O uso de práticas da Lean Startup levam a modelos de negócios mais maduros?” a seguir são analisadas de forma exploratória as relações entre as variáveis. Ainda para investigar o tempo do início do planejamento até o primeiro teste com clientes, essa variável foi analisada em conjunto com a "obtenção de investimentos de terceiros". Embora alguns empreendedores não necessitem de recursos de terceiros, a obtenção de tais recursos exige uma maturidade do modelo de negócios e pode ser entendido como um primeiro passo no caminho para o sucesso do empreendedor, significa que terceiros analisaram a empresa e encontraram um potencial, mas não significa necessariamente que as empresas que não receberam recursos não possuem modelos de negócios maduros, pode ter sido uma opção do empreendedor. As empresas que receberam investimentos fizeram testes mais cedo, em média os primeiros testes foram com 5,8 meses. Enquanto as empresas que não receberam investimentos, fizeram os primeiros testes com 7,2 meses. Aqui não é possível afirmar se a busca por capital exige que os empresários façam testes mais cedo ou se o teste mais cedo facilita a busca por capital.

Para garantir a relevância da análise acima, é importante destacar que o número de empresas que receberam investimento é 54 , valor muito próximo ao de empresas que não receberam investimentos externos (60). Além disso é importante destacar que esses dois grupos possuem média de idade próximas, as empresas que receberam investimentos possuem média de idade de 23,3 meses, enquanto a média de idade das empresas que não receberam investimentos é de 21,1 meses.

O uso de métricas Lean foi comparado também com a variável captação de recursos. Entre as startups que não receberam investimentos, a minoria utiliza métricas Lean (47\%). Entre as empresas que receberam investimentos, a maioria utiliza as métricas Lean (61\%).

A variável "estágio de desenvolvimento do produto ou serviço nos primeiros testes com os clientes" também foi comparada com o recebimento de investimentos externos, a média do estágio de maturidade nos primeiros testes para o grupo que não recebeu investimentos é de 3,7 , enquanto a média do grupo que recebeu investimentos é de 4,2 - esse resultado está aderente às recomendações de Ries (2012), pois as empresas que captaram recursos externos fizeram os primeiros testes com clientes com produtos/protótipos mais simples.

Foi analisada ainda a relação da variável "recebeu investimento externo" com "a empresa já ter mudado mais seu modelo de negócios", o resultado também não permite afirmações, pois as médias estão próximas. Para as empresas que não receberam investimentos a média foi de 3,3 na variável da 
empresa já ter mudado muito, frente uma média de 3,4 nas empresas que não receberam investimentos. Foi analisada também a relação entre o índice de maturidade do modelo de negócios com a questão 11, que pergunta o quanto o empreendedor concorda com a afirmação que é a base do Lean (BREUER, 2013; BLANK; DORF, 2012; RIES 2012).

Ao comprar a variável "ter recebido recursos externos" com a afirmação sobre o objetivo da startup, o resultado foi contrário ao esperado (embora a diferença tenha sido muito pequena, pois a média na resposta sobre os objetivos foi mais alta para as empresas que não receberam investimentos $(3,9) \mathrm{em}$ comparação com as empresas que receberam investimentos $(3,7)$.

Também foram comparadas as variáveis demográficas com a obtenção de investimentos externos e aparentemente empreendedores com maior experiência em anos na atividade empreendedora e números de projetos que já participou influenciam de forma positiva a obtenção de recursos. Dentro do grupo das empresas que captou investimentos externos a média de experiência do empreendedor é de 8,6 anos e a média empresas que os indivíduos desse grupo abriram é de 2,5. Enquanto no grupo das startups que não captaram recursos, o empreendedor tem em média 5,3 anos de experiência e a média de empresas que foram abertas é de 1,9. O gráfico abaixo demonstra essas comparações.

Com o objetivo de analisar de forma conjunta a relação entre as práticas da Lean Startup e a variável dependente (índice de maturidade do modelo de negócios), o passo seguinte foi a construção de uma análise de regressão linear múltipla. O coeficiente de determinação $\left(\mathrm{R}^{2}\right)$ foi de $5,54 \%$, considerado baixo. Para verificar se suas variáveis estão correlacionadas, também foi observado o VIF, como todos os coeficientes possuem VIF menores do que 5, nenhum foi excluído por essa razão. Também analisamos os resíduos em busca de outliers (valores acima de três), entretanto nenhum caso foi encontrado.

Foi feito também um teste de significância do modelo. Esse teste analisa a probabilidade de os coeficientes da regressão serem iguais a zero. Então um alto p-valor significa que os resultados obtidos possuem uma grande chance de terem sido obtidos ao acaso. Os p-valores dos coeficientes "Usa métrica Lean", "Essa métrica guiou alguma mudança", "Nos primeiros testes qual a maturidade do produto/serviço", "O modelo de negócios passou por muitas mudanças" e "Objetivo principal da empresa é o aprendizado" são maiores do que $10 \%$.

Sendo assim a hipótese nula não pode ser descartada para todas essas variáveis, podemos descartar a hipótese nula somente para "quanto tempo levou do início do planejamento até os primeiros testes com os clientes", que possuí um coeficiente relacionado positivamente com o índice de maturidade. Esse resultado é contrário ao esperado, pois significa que quanto mais tempo levou dos primeiros testes com os clientes, mais alto o índice de maturidade do modelo de negócios.

Foi feita também uma regressão logística binária (probit) para analisar a relação entre as práticas da Lean Startup e as variáveis demográficas com a startup ter recebido ou não recursos de terceiros. Conforme já mencionado, a obtenção de tais recursos exige uma maturidade do modelo de negócios e pode ser entendido como um primeiro passo no caminho para o sucesso do empreendedor, significa que terceiros analisaram a empresa e encontraram um potencial. Essa variável, diferente do índice de maturidade, consegue diferenciar bem as empresas além de ser objetiva.

O coeficiente de determinação $\left(\mathrm{R}^{2}\right)$ foi de $16,1 \%$, ou seja, essa é a variação em "A startup recebeu recursos de terceiros" que pode ser explicada pelo modelo. Entretanto, mais importante do que esse indicador são os p-valores, que foram:

0,087 Tempo do início do planejamento até o primeiro teste

0,054 Principal métrica é Lean

0,730 Essa métrica guiou alguma mudança

0,033 Nos primeiros testes qual a maturidade do produto/serviço

0,815 O modelo de negócios passou por muitas mudanças

0,990 Objetivo principal da empresa é o aprendizado

0,023 Idade da startup

0,151 Tempo de experiência do empreendedor

0,022 Número de empresas que o empreendedor já fundou 
Diante desse resultado, foi aceita a hipótese nula para as variáveis "Essa métrica guiou alguma mudança", "O modelo de negócios passou por muitas mudanças", "Objetivo principal da empresa é o aprendizado", "Tempo de experiência do empreendedor", ou seja, os resultados obtidos para essas variáveis podem ter ocorrido ao acaso. Entretanto, para todas as demais variáveis (grifadas), foi rejeitada a hipótese nula, pois os p-valores são maiores do que 0,10.

Com isso, podemos analisar os coeficientes dessas variáveis. Para "Tempo do início do planejamento até o primeiro teste" o resultado obtido está aderente às práticas da Lean Startup, pois um coeficiente de sinal negativo significa que as startups que receberam recursos de terceiros tiveram menos tempo entre o início do planejamento e os primeiros testes com clientes.

Para a variável "Principal métrica é Lean" o resultado obtido também está de acordo com o esperado, pois significa o uso de tais métricas está relacionado com as empresas captarem recursos de terceiros. O resultado obtido pela variável "Nos primeiros testes qual a maturidade do produto/serviço" também está aderente às recomendações de Ries (2012) e Blank e Dorf (2012), pois significa que o fato de nos testes iniciais com os clientes a startup ter usado protótipos/produtos mais simples está relacionado com o fato da empresa ter captado recursos de terceiros.

O número de empresas que o empreendedor já fundou e a idade da startup também parecem também estarem positivamente relacionados com o fato da startup ter recebido recursos de terceiros, esse resultado não está relacionado com as práticas Lean, pois essas são variáveis demográficas, e qualquer forma esse era o resultado esperado, pois faz sentido lógico.

\section{Considerações finais}

Com o objetivo de explorar a utilização e o conhecimento da metodologia "Lean Startup", enquadrada dentro da perspectiva do empreendedorismo como método, foi feita uma survey com 115 empreendedores, sócios de empresas de base tecnológica com até 42 meses de existência.

Como forma de análise foram utilizadas estatísticas descritivas, uma regressão linear múltipla que não apresentou resultados satisfatório e uma regressão logística binária (probit) que resultou em 5 variáveis com p-valores menores do que 0,10 , ou seja, com confiabilidade de $90 \%$ de que os resultados não ocorreram por acaso. Todas as afirmações feitas nesse capítulo referem-se aos 115 elementos da amostra, sem a intenção de generalizar para todos os empreendedores do Brasil.

A análise de regressão logística confirma que a idade da startup e o número de empresas que o empreendedor já fundou influenciam positivamente na captação de recursos de terceiros, pois os pvalores são menores do que 0,10 e os sinais dos coeficientes são positivos.

Dada a falta de um framework para medir o quanto a empresa é aderente às métricas Lean e também para medir os resultados dessas práticas, o autor do presente estudo propôs alguns indicadores, que foram utilizados de forma exploratória e devem ser testados em estudos futuros, eles são resumidos nos parágrafos seguintes.

Um dos indícios encontrados na amostra analisada foi de que as práticas da Lean Startup são amplamente difundidas, 93\% dos entrevistados afirmaram conhecer a metodologia. Quando questionadas sobre onde aprenderam sobre a metodologia, essas pessoas afirmaram que foi principalmente a partir de livros e matérias na internet, com um pouco menos de frequência mencionaram também vídeos na internet e palestras. Das opções oferecidas como fonte de aprendizado sobre as técnicas, na "faculdade" foi o de menor frequência, sendo assim, conclui-se que embora alguns importantes MBAs internacionais utilizem a Lean Startup em seus cursos, as Instituições de Ensino Superior brasileiras, nas quais os empreendedores estudaram, parecem ignorála até a data do presente estudo.

Em suma, a Lean Startup é muito conhecida pelos empreendedores, embora os estudos acadêmicos sobre a metodologia sejam quase inexistentes. Suas práticas são amplamente adotadas, $71 \%$ dos respondentes concordam com que o principal objetivo de uma startup é o aprendizado, $65 \%$ dos respondentes afirmam que sua principal métrica é uma das recomendas por Ries (2012), 46\% das startups passaram por muitas mudanças em seus modelos de negócios (pivotagem/iterações) e 45\% 
das empresas utilizaram um PMV. Foram encontrados sinais de resultados positivos (medidos pela captação ou não de recursos) na aplicação de: a) feedback acelerado - realização de testes com clientes para obtenção de feedback o mais cedo possível; b) PMV - utilização de um produto mínimo viável nos primeiros testes com os clientes; c) métricas da contabilidade para inovação - que medem o aprendizado e não resultados financeiros.

Como essas práticas parecem ter uma maior relação com a obtenção de resultados positivos, sobre elas devem prestar uma atenção especial os estudos futuros sobre a Lean Startup. Não foram encontradas evidências quanto a obtenção de resultados positivos (nem negativos) pela realização de pivotagens, mudanças guiadas pelas métricas, bem como pela concordância dos empreendedores com a afirmação que é a base da Lean Startup, de que o principal objetivo inicialmente é o aprendizado.

\section{Referências}

AHMAD, Nadim; SEYMOUR, Richard G. Defining entrepreneurial activity: definitions supporting frameworks for data collection. OECD Publishing, 2008.

ALRECK, Pamela L.; SETTLE, Robert B. The Survey Research Handbook: Guidelines and Strategies for Conducting a Survey, 2E. 1995.

BAKER, Ted; MINER, Anne S.; EESLEY, Dale T. Improvising firms: bricolage, account giving and improvisational competencies in the founding process. Research policy, v. 32, n. 2, p. 255-276, 2003. BAKER, Ted; NELSON, Reed E. Creating something from nothing: Resource construction through entrepreneurial bricolage. Administrative science quarterly, v. 50, n. 3, p. 329-366, 2005.

BLANK, Steve. The four steps to the epiphany: Successful Strategies for Products that Win. 4. ed. Quad/Graphics, 2007.281 p.

BLANK, Steve. Why the Lean Startup changes everything. Harvard Business Review, v. 91. n. 5, p. 63-72, 2013.

BLANK, Steve; DORF, Bob. The Startup Owner's Manual. 1. ed. Pescadero, CA: K\&S Ranch Press, 2012. $571 \mathrm{p}$.

BRINCKMANN, Jan; GRICHNIK, Dietmar; KAPSA, Diana. Should entrepreneurs plan or just storm the castle? A meta-analysis on contextual factors impacting the business planning-performance relationship in small firms. Journal of Business Venturing, v. 25. n. 1, p. 24-40, 2010.

CHANDLER, Gaylen N. et al. Causation and effectuation processes: A validation study. Journal of Business Venturing, v. 26, n. 3, p. 375-390, 2011.

CRESWELL, John W. Projeto de Pesquisa: Metodos Qualitativo, Quantitativo e Misto. 3. ed. Porto Alegre: Artmed, 2010.296 p.

DEMO BRASIL 2014, http://www.demobrasil.com.br/, acessado em 21 de setembro de 2014.

DEY, Anind K.; ABOWD, Gregory D.; SALBER, Daniel. A conceptual framework and a toolkit for supporting the rapid prototyping of context-aware applications. Human-computer interaction, $v$. 16, n. 2, p. 97-166, 2001.

DEW, Nicholas; SARASVATHY, Saras D.; VENKATARAMAN, Sankaran. The economic implications of exaptation. Journal of Evolutionary Economics, v. 14, n. 1, p. 69-84, 2004.

DEW, Nicholas et al. On the entrepreneurial genesis of new markets: Effectual transformations versus causal search and selection. Journal of Evolutionary Economics, v. 21, n. 2, p. 231-253, 2011.

GRUBER, Marc. Uncovering the value of planning in new venture creation: A process and contingency perspective. Journal of Business Venturing, v. 22, n. 6, p. 782-807, 2007.

MAXWELL, Andrew L.; JEFFREY, Scott A.; LÉVESQUE, Moren. Business angel early stage decision making. Journal of Business Venturing, v. 26, n. 2, p. 212-225, 2011.

OSTERWALDER, Alexander; PIGNERU, Yves. Inovação em Modelo de Negócios: Business Model Generation. 1. ed. São Paulo: Alta Books, 2011. 300 p.

PETTY, Jeffrey S.; GRUBER, Marc. In pursuit of the real deal: A longitudinal study of VC decision making. Journal of Business Venturing, v.26, n. 2, p. 172-188, 2011. 
RIES, Eric. A Startup Enxuta. 1. ed. São Paulo: Leya Brasil, 2012. 224 p.

SALUSSE, Marcus Alexandre Yshikawa. O ensino de empreendedorismo com fundamento na teoria effectuation. 2014. 203 f. Dissertação (Mestrado) - Curso de Mestrado em Administração de Empresas, Fundação Getúlio Vargas - Escola de Administração de Empresas de São Paulo, São Paulo, 2014.

SARASVATHY, Saras D. Causation and effectuation: Toward a theoretical shift from economic inevitability to entrepreneurial contingency. Academy of management Review, v. 26, n. 2, p. 243263, 2001.

SARASVATHY, Saras D.; DEW, Nicholas. New market creation through transformation. Journal of Evolutionary Economics, v. 15, n. 5, p. 533-565, 2005.

SARASVATHY, S. D.; VENKATARAMAN, S. Entrepreneurship as Method: Open Questions for an Entrepreneurial Future. Entrepreneurship Theory and Practice, v. 35, n. 1, p. 113-135, 17 jan. 2011.

SAUNDERS, Mark; LEWIS, Philip; THORNHILL, Adrian. Research methods for business students. 5. ed. Pearson Education Limited: England, 2009.

SCHRAGE, Michael. The culture (s) of prototyping. Design Management Journal (Former Series), v. 4, n. 1, p. 55-65, 1993.

SHANE, Scott. Reflections on the 2010 AMR decade award: delivering on the promise of entrepreneurship as a field of research. Academy of Management Review, v. 37, n. 1, p. 10-20, 2012.

TETHER, Bruce S. Small firms, innovation and employment creation in Britain and Europe: A question of expectation. Technovation, v. 20, n. 2, p. 109-113, 2000.

THOMKE, Stefan; VON HIPPEL, Eric. Innovators. Harvard business review, v. 80, n. 4, p. $74-$ 81, 2002.

VENKATARAMAN, Sankaran. The distinctive domain of entrepreneurship research. Advances in entrepreneurship, firm emergence and growth, v. 3, n. 1, p. 119-138, 1997.

VENKATARAMAN, Sankaran et al. Reflections on the 2010 AMR decade award: Whither the promise? Moving forward with entrepreneurship as a science of the artificial. Academy of Management Review, v. 37, n. 1, p. 21-33, 2012.

VENKATARAMAN, Sankaran et al. Of narratives and artifacts. Academy of Management Review, v. 38, n. 1, p. 163-166, 2013.

WENNEKERS, Sander; THURIK, Roy. Linking entrepreneurship and economic growth. Small Business Economics, v. 13, n. 1, p. 27-56, 1999.

WILTBANK, Robert; SUDEK, Richard; READ, Stuart. The role of prediction in new venture investing. Frontiers of Entrepreneurship Research, v. 29, n. 2, art. 3, 2009. 